\title{
Ocorrência de intoxicação aguda em bovinos pela samambaia (Pteridium aquilinum, L. Kuhn) no norte do Paraná-Brasil
}

\section{Cattle acute intoxication by bracken fern (Pteridium aquilinum, L. Kuhn) at north Paraná State-Brazil}

\author{
Wilmar Sachetin Marçal'; Laurenil Gaste2; Ney Carlos Reichert Netto²; Marcelo Carlos Gargantini \\ Marques $^{3}$; Reginaldo Pontes Fernandes ${ }^{4}$; Alexandre Amorim Monteiro ${ }^{5}$
}

\begin{abstract}
Resumo: Os autores descrevem a ocorrência de um surto de intoxicação aguda pela samambaia (Pteridium aquilinum, L. Kuhn), em bovinos, criados numa propriedade rural localizada no município de Reserva, estado do Paraná. Um total de 25 animais foram a óbito. A ocorrência da intoxicação teve, muito provavelmente, uma relação direta com as freqüentes e acentuadas geadas ocorridas no mês de julho de 2000. Além do relato clínico, os autores apresentam considerações a respeito da proliferação da samambaia no Paraná, destacando condições ambientais e climáticas favorecedoras dessa disseminação, bem como os prejuízos à pecuária e as conseqüências da presença desse vegetal tóxico nas pastagens paranaenses.
\end{abstract}

Palavras-chave: bovinos, intoxicação, samambaia, Pteridium aquilinum.

Abstract: The authors describe a case of acute intoxication by bracken fern (Pteridium aquilinum) in a cattle herd raised in the city of Reserva, Parana State. A total of 25 animals died due to intoxication caused by the ingestion of large amounts of the toxic plant after the occurrence of a frost period in the winter month of July, 2000. Beside the herd clinical case, the authors present some considerations about the spreading of bracken fern in Parana, with particular interest in the environmental conditions (including weather). We suspect that these conditions can facilitate the spread of the plant during the cold months of the year. More plant available means a favorable situation for the bracken fern animal consumption, then causing losses to the cattle industry.

Key words: cattle, poisoning, bracken, Pteridium aquilinum.

\section{Introdução}

O Estado do Paraná, com efetivo bovino de quase 10 milhões de cabeças (IBGE, 1998 apudBRASIL, 2000), apesar de ser considerado e amparado por alta tecnologia agropecuária, demonstra, ainda, alguns problemas na criação animal, apresentando graves enfermidades relacionadas a ingestão de vegetais tóxicos (MARÇAL, 1990; MARÇAL, 2000).

De grande repercussão nesse enfoque, destaca-se a Pteridium aquilinum ou Pteris aquilina, planta tóxica popularmente conhecida por samambaia dos campos, ou simplesmente samambaia (TOKARNIA et al., 1979; TOKARNIA et al., 2000). Trata-se de um vegetal de característica invasora, sendo bastante freqüente em solos ácidos, arenosos e de baixa fertilidade. Infesta campos, matas ciliares, capoeiras, beiras de matos e de estradas. Na Finlândia, calcula-se que clones individuais da planta existem há mais de 650 anos e que a remoção da cobertura florestal cria habitat ideal para a invasão da samambaia (OINONEN, 1967), mantendo-se exuberante em ambientes onde há pouca competição (POLACK, 1990).
A Pteridium aquilinum é um dos vegetais tóxicos mais preocupantes em vários países do mundo, incluindo o Brasil. Por causar enfermidades que acometem rebanhos de bovinos (TOKARNIA et al., 1979; NIERO et al., 1991; TOKARNIA et al., 2000), tem sido considerada a planta tóxica que causa o maior prejuízo à pecuária bovina paranaense, ocorrendo em 105 municípios (POLACK, 1990), dos 399 existentes (FERREIRA, 1996). Embora em algumas fazendas as pastagens sejam renovadas, ainda assim, persiste a samambaia, em proporções que variam de, no mínimo, brotos quase imperceptíveis à arbustos bem desenvolvidos (OLIVEIRA et al., 1998).

A toxidez pela samambaia nos bovinos pode se manifestar de forma superaguda, aguda, subaguda $e$ crônica (SOUZA; GRAÇA, 1993), sendo que os quadros agudos ocorrem pela ingestão da planta em quantidades diárias superiores a $10 \mathrm{~g} / \mathrm{kg}$ de peso por períodos que variam de 3 semanas a poucos meses (GIBBONS, 1956). A forma crônica de manifestação tóxica caracteriza-se pela Hematúria Enzoótica e pela formação de carcinomas epidermóides no trato digestivo superior, necessitando que os bovinos consumam uma quantidade maior

\footnotetext{
${ }^{1}$ Médico veterinário, mestre em Patologia Bovina, Doutor em Clínica: Fisiopatologia Médica, Professor do Curso de Medicina Veterinária, Universidade Estadual de Londrina, Caixa Postal 6001, cep: 86051-970, Londrina - PR. Autor para correspondência. E-mail: wilmar@uel.br 2 Professor do Curso de Medicina Veterinária, Universidade Estadual de Londrina.

${ }^{3}$ Médico veterinário, residente em Medicina Veterinária na Universidade Estadual de Londrina.

${ }^{4}$ Médico Veterinário autônomo, Maringá - PR.

${ }^{5}$ Acadêmico de Medicina Veterinária da Universidade Estadual de Londrina.
} 
da planta por longos períodos (CAMPOS NETO et al., 1975; TOKARNIA et al., 1979; TOKARNIA et al., 2000). Nos quadros tóxicos não há predisposição por raça (PAMUKCU et al., 1976), ou mesmo sexo (HOPKINS, 1986). No Brasil, os primeiros casos de Hematúria enzoótica dos bovinos foram relatados por Bueno (1953) como papilomatose faringeana, e por Lacaz (1954) nas observações de cistite com presença de hemácias na urina.

Todas as partes da samambaia contém os princípios tóxicos em forma ativa, sendo o broto a porção mais tóxica de suas partes aéreas e o rizoma a parte da planta que possui maior atividade carcinogênica (HIRONO et al., 1973). A brotação que surge após as queimadas ou geadas é muito temida e perigosa, pois concentra uma grande quantidade dos princípios tóxicos da planta. Esse aspecto indica que a planta torna-se ainda mais perigosa para os bovinos criados extensivamente, determinando quadros agudos de toxidez (MARÇAL, 2000), principalmente quando há superlotação de pastagens (PARKER; McCREA, 1965).

Conforme destaca Hopkins (1986), a planta possui os seguintes princípios tóxicos: tanino; quercetina; ácido chiquímico; prumasina; ptaquilosideo; aquilideo A e canferol. Segundo Polack (1990) muitos estudos vem sendo conduzidos para se conhecer outros princípios tóxicos da planta, já tendo ocorrido o isolamento de diversos ácidos orgânicos como o ácido dicafeiltartárico (chicoric acid), pelo menos cinco flavonóides, perto de 30 pterosina-sesquiterpenos e, também, polissacarídeos, glicosídios, astragalinas, isoquercetina, catecolaminas e pteraquilina. Sobre o ptaquilosídeo, RietCorrea et al. (1993) afirmam se tratar de um glicosídeo norsesquiterpeno que contribui significativamente para a ação mutagênica e carcinogênica da Pteridium aquilinum. Clarke e Clarke (1975); Tokarnia et al. (1979) e Tokarnia et al. (2000), mencionam ainda a existência da tiaminase, muito representativa toxicologicamente aos eqüinos, determinando quadro clínico neurológico, embora a toxidez naquela espécie seja rara de ocorrer nas condições brasileiras (MARÇAL; CAMPOS NETO, 1996; MARÇAL, 2000). Já em 1942 Goetze apud Reichmann (1975), supunha existir na samambaia além da tiaminase, um veneno vascular causador da diátese hemorrágica. Esta fase clínica da doença é popularmente conhecida por "suor de sangue" (MARÇAL, 1990); (NIERO et al., 1991), referindo-se a uma manifestação clínica de hematidrose (MARÇAL, 2000).

Ainda sobre os princípios tóxicos, Singh et al. (1980) destacam que, num experimento com bovinos de 2 a 4 anos, animais com manifestação clínica de hematúria, apresentaram valores aumentados de uma mucoproteina e do ácido siálico. Segundo os autores, essas substâncias possuem forte ligação com o crescimento neoplásico das células da bexiga, responsável pela hematúria naqueles bovinos.

Nos casos de manifestação aguda e subaguda, Tokarnia et al. (1967), ao vivenciarem um surto, relataram que podem ocorrer erosões nas narinas e focinho, além de ulcerações na mucosa do intestino delgado e grosso.
Basile et al. (1981) relataram a ocorrência da forma aguda de intoxicação em 16 bovinos na região de Londrina, estado do Paraná, onde os óbitos de todos os animais ocorreram entre um a três dias após o inicio dos sintomas clínicos, sobretudo de diátese hemorrágica. Niero et al. (1991), relataram um surto de toxidez aguda pela samambaia em Tamarana, estado do Paraná. Na oportunidade, final de inverno de 1990, 42 machos e 5 fêmeas da raça nelore, com faixa etária de 12 a 36 meses de vida, vieram a óbito. Os principais sintomas observados pelos autores, em alguns animais antes da morte e na necrópsia, foram hematidrose, epistaxis, hemorragias nas mucosas e serosas, petéquias e sufusões na pleura e peritonio visceral, nos intestinos e rúmen.

Oliveira et al. (1998), em pesquisa requisitada por pecuaristas da região nordeste do Paraná, verificaram pela anamnese, nos municípios de Santo Antônio da Platina, Ibaiti e Arapoti, que o problema da toxidez pela planta era mais freqüente nos animais de primeira cria, na faixa etária de 4 a 5 anos. Os bovinos apresentavam urina com coloração avermelhada, emagrecimento progressivo e prostração, com quadro clínico irreversível, culminado com óbito no período de 10 a 60 dias.

Segundo Yamane et al. (1975), na toxidez aguda pela samambaia em bovinos, há também um aumento de fragilidade capilar e no tempo de sangramento, e uma diminuição na retração do coágulo, que pode ser evidenciado com base na trombocitopenia e no aumento do fibrinogênio.

Pelas observações de Durão et al. (1995), a intoxicação aguda é caracterizada por uma síndrome hemorrágica, levando os animais a óbito em torno de 12 a 72 horas após o aparecimento dos primeiros sinais clínicos.

Ainda com relação aos episódios de toxidez aguda pela samambaia, Polack (1990), observou, em alguns animais do rebanho bovino paranaense, que os quadros agudos de toxidez estavam associados a intensidade de ocorrência da Pteridium aquilinum nas pastagens das fazendas, sendo que o maior número de mortes ocorreram em municípios onde a intensidade da planta foi considerada de moderada a alta.

Hayashi (1981) relatou que as alterações hematológicas em bovinos intoxicados, revelam depressão da atividade da medula óssea com trombocitopenia e leucopenia e que a diminuição na contagem plaquetária está associada a diminuição na contagem de megacariócitos, comprovada pela biópsia de medula óssea.

O agente tóxico da planta parece retardar mitoses vistas particularmente em tecidos proliferativos como aqueles que contem células tronco como o tecido linfático, tecido hematopoiético, séries espermatogênicas e no epitélio intestinal (KITAHARA et al., 1974 apud HUMPHREYS et al., 1988).

Com relação a manifestação sazonal, Musca et al. (1997), trabalhando com bovinos na Romênia, detectaram uma maior incidência de manifestações clínicas nas estações do verão e outono. Tokarnia et al. (1967), 
ao presenciarem um surto de toxidez pela samambaia, associaram a escassez de pastagens no inverno e a presença da planta na propriedade rural com a ocorrência do episódio.

Marçal (2000) destaca que, no Brasil, ocorre uma maior manifestação clínica de surtos agudos na época do inverno, devido a escassez das pastagens e pelo fato da samambaia suportar bem a seca. Segundo o autor, a planta tem se disseminado porque encontra condições edafo-climáticas favoráveis para ocupar terras não mecanizáveis, mas que servem como pastagem ao rebanho bovino.

Neste trabalho, o objetivo é relatar a ocorrência de um surto agudo de toxidez pela samambaia em bovinos criados em propriedade rural do município de Reserva, estado do Paraná. Além disso, os autores apresentam, também, considerações a respeito da proliferação da samambaia no Estado, com destaque para as condições ambientais e climáticas favorecedoras dessa disseminação, bem como os prejuízos e as conseqüências da presença desse vegetal tóxico nas pastagens paranaenses.

\section{Material e Métodos}

O período crítico da ocorrência do surto se deu entre 05 e 10 de novembro de 2000, numa propriedade rural localizada no município de Reserva, estado do Paraná com latitude $24^{\circ} 39^{\prime} 05^{\prime \prime}$, longitude $50^{\circ} 50^{\prime} 40^{\prime \prime}$ e altitude 850 m (FERREIRA, 1996). O relevo da região é classificado como sendo irregular, com aclives e declives, característico de uma região acidentada topograficamente. Essa região inicia-se a oeste da serra Geral e termina no rio Paraná, possuindo grande extensão de terras. As altitudes variam de 197 a 1.250 metros e a sua vegetação é muito diversificada. Fazem parte desse tipo de floresta o palmito, a peroba, o pau-d'alho, o cedro, a figueira branca, a imbuia e o ipê-roxo (TUMA, 1992). O clima é sub-tropical úmido mesotérmico, de verões frescos e com ocorrência de geadas severas e freqüentes, não apresentando estação seca bem definida. A média de temperatura dos meses mais quentes é inferior a $22^{\circ} \mathrm{C}$, e a dos meses mais frios é inferior a 18ํㅡ (FERREIRA, 1996).

A fazenda concentra atividades em exploração extensiva, com bovinos de diferentes raças, tendo na época 252 cabeças, onde a maioria do rebanho era constituída de vacas de cria mestiças, além da raça Nelore e algumas da raça holandesa preta e branca, para fornecimento de leite aos empregados da fazenda. A planta sempre existiu na propriedade e nos últimos cinco anos se disseminou muito, apesar de algumas roçadas em locais possíveis de acesso. Na constatação a campo, percorrendo a fazenda e regiões adjacentes, percebemos que mata nativa e cobertura florestal praticamente inexistem.

As pastagens predominantes eram Brachiaria decumbens e Brachiaria brizantha, sendo que a primeira ocupa a maior parte das pastagens na propriedade. A mineralização e a água eram fornecidas ad libitum, sendo os sais minerais adequadamente equilibrados quanto aos macro e microelementos, conforme recomendações após análises de solo. Os animais receberam também uma alimentação suplementar, a base de sal mineral proteinado, logo após a ocorrência de geadas, que dizimaram as pastagens já prejudicadas pelo período de seca que as antecedeu. A alimentação mineralizada era fornecida em cochos apropriados e cobertos, bem distribuídos nos piquetes e em bom estado de conservação.

\section{Resultados e Discussão}

A ocorrência de geadas fortes na região aconteceu entre os dias 13 e 24 de julho de 2000 , sendo que nos dias 13, 14, 17, 20 e 21 constatou-se os mais elevados índices do fenômeno, com temperaturas extremamente baixas na relva (IAPAR, 2001).

Após este período crítico, houve alguns episódios de chuva, seguidos de dias ensolarados, o que contribuiu para que houvesse uma recuperação da vegetação, sobretudo as pastagens. Porém, a brotação da samambaia ocorreu mais rapidamente, antecedendo as pastagens, tornando-se atrativas aos bovinos que, criados extensivamente, procuraram a planta para se saciarem (MARÇAL, 2001).

Ainda durante o episódio do surto, conforme observado "in loco", foi possível perceber que os animais comeram grandes quantidades da planta, principalmente os brotos que ficam sempre em porções aéreas da rebrota.

Os principais sintomas observados em alguns bovinos, ainda vivos, além dos relatos de anamnese, eram de uma síndrome hemorrágica, acompanhada por aumento da temperatura corporal extremamente alta, coerente com as observações de Hagan (1952). Os animais acometidos demonstravam hemorragias pela pele e mucosas visíveis, corrimento nasal muco sanguinolento e diarréia com sangue. Esses sinais clínicos são compatíveis com as descrições de Tokarnia et al., 1979; Basile et al. (1981); Niero et al. (1991). A morte ocorria rapidamente, num prazo de até 72 horas após o início dos sintomas, mesmo período observado por Tokarnia et al. (1967); Basile et al. (1981); Niero et al. (1991); Durão et al. (1995) e Tokarnia et al. (2000).

Enfermidades com sintomatologia semelhantes foram consideradas e descartadas no diagnóstico diferencial, com especial atenção para a Pasteurelose (TOKARNIA et al., 1979), Babesiose e Anaplasmose, Leptospirose, intoxicação por Crotalaria sp, intoxicação por trevo doce mofado, Hemoglobinúria bacilar (POLACK, 1990), Carbúnculo hemático e a síndrome produzida por irradiação ionizante (HAGAN, 1952; SIPPEL, 1952; EVANS, 1954a, b, c).

Três bovinos, com prognóstico desfavorável, foram eutanaziados na própria fazenda, para análise e colheita de material, com vistas à análise laboratorial. Durante a necrópsia pode-se perceber lesões hemorrágicas do 
tecido celular subcutâneo, hemorragias no baço, intestino e bexiga, além de úlceras nas mucosas. $\mathrm{O}$ trato digestivo apresentava edema e vários pontos hemorrágicos, bem como a presença de fragmentos da samambaia no interior do rúmen. Estas observações são compatíveis com as descrições de Tokarnia et al. (1979); Basile et al. (1981); Niero et al. (1991) e Durão et al. (1995)

A histopatologia revelou rarefação do tecido hematopoiético na medula óssea, com acentuada diminuição do número de células, depressão da série megacariocítica e granulocítica, alterações estas compatíveis com as descrições de outros autores (EVANS et al., 1954a,b,c; TOKARNIA et al., 1967; TOKARNIA et al., 1979; NIERO et al., 1991; TOKARNIA et al., 2000). As alterações mais significativas ao exame hematológico, nos três bovinos em que foi possível a colheita, foram trombocitopenia e leucopenia, dados estes compatíveis com citações de outros autores (EVANS et al., 1954;a,b,c; EVANS; HOWELL, 1962; NIERO et al., 1991; MARÇAL; CAMPOS NETO, 1996)
Os dados gerais dos animais que vieram a óbito encontram-se destacados no Quadro 1.

A conduta para se evitar novos casos naquela propriedade foi dedicar atenção especial à profilaxia, para minimizar a ocorrência da enfermidade na localidade. Com esta finalidade foi recomendado a retirada imediata de bovinos dos piquetes que tivessem a samambaia, isolando áreas, pois com isso, evitar-seia o vício que os bovinos adquirem (TOKARNIA et al., 1979), prevenindo-se novos surtos. Além disso, foi recomendado o arrancamento da planta na época da rebrota (MARÇAL, 2000), bem como a calagem do solo para correção da acidez, para plantio de capim.

A questão do relevo e clima naquela região, constituise numa grande barreira para a erradicação da samambaia na localidade de Reserva, local da ocorrência deste surto. As propriedades rurais, na grande maioria, são de criação extensiva, com topografia irregular, não permitindo mecanização agrícola.

Quadro 1 - Dados Gerais dos bovinos vitimados pela samambaia em propriedade rural do município de Reserva, estado do Paraná. 
A baixa fertilidade do solo constituiu-se num outro fator de extrema facilidade para a disseminação da samambaia naquela localidade, pois a Pteridium aquilinum é pouco exigente para se proliferar (TOKARNIA et al., 1979; NIERO et al., 1991; MARÇAL, 2000). Com pouca competitividade vegetativa, a planta encontrou um ambiente propício para sua exuberância. As terras foram, então, utilizadas como pastagens, cujo cultivo agrícola foi feito com capim Brachiaria decumbens, gramínea pouco exigente em relação ao solo para se disseminar (MARÇAL et al., 1991; MARÇAL; CAMPOS NETO, 1996). Esta cultura de gramas foi executada no passado a custa de desmatamentos e devastações de matas nativas (MARÇAL, 2001). Estas condições ambientais tornaram a samambaia, naquela região e adjacências, a planta tóxica mais temível para a pecuária bovina, acarretando enormes prejuízos. O mais preocupante é que o aumento da retirada da cobertura florestal, vem criando um habitat favorável para uma maior disseminação da samambaia para outras regiões. A disseminação avança para muitas outras localidades, já que ela é considerada uma planta daninha extremamente invasora (TOKARNIA et al., 1979; POLACK, 1990; MARÇAL; CAMPOS NETO, 1996).

Por essas razões, a questão da sazonalidade apresentada neste trabalho, ou seja, a ocorrência do surto após geada, talvez não tivesse tanta importância em outros tempos, onde, apesar da existência da samambaia, haviam outras pastagens, nativas ou cultivadas, como alternativas atóxicas para a alimentação do gado. Mas, ao longo dos anos, esse panorama vem mudando. A planta está se disseminando muito rapidamente, ocupando cada vez maiores áreas. Por isso, se tornou alternativa de alimento ao gado com a rebrota após a geada. Polack (1990), em pesquisa epidemiológica no estado do Paraná, já alertava para o fato de que a Pteridium aquilinum progrediu muito no estado, porque alia à interferência universal e desinformada do homem no meio ambiente, criando ainda mais áreas desocupadas, sem respeitar as implicações ecológicas. O problema da difusão da samambaia, conforme destaca a mesma autora, foi claramente criado pelo próprio homem e, talvez apenas a restauração do equilíbrio ecológico natural para a comunidade vegetal, asseguraria o seu controle. Lamentavelmente muitos surtos ainda irão surgir, pois isto demandaria um longo prazo (PAGE, 1976). As observações de campo em outros municípios, igualmente vulneráveis à ação da planta, também condiz com a gravidade dessa disseminação apontada no levantamento epidemiológico de Polack (1990). Oliveira et al. (1998), enfatizam que as perdas mediante as mortes e o descarte dos bovinos em municípios próximos aos da ocorrência deste surto, atingem, valores mensais de 4 a $5 \%$, por propriedade rural.

Nesta região do estado do Paraná, sempre houve histórico de acometimento da saúde animal pela samambaia (MARÇAL, 2001). A questão do relevo, clima, solo, entre outros, deveriam ser considerados, quando se planeja a criação extensiva de bovinos naquelas terras. Talvez a serventia da mesma seja imprópria para a pecuária e os sucessivos erros e a insistência do homem em ocupar os espaços, cuja finalidade não se apregoa, podem estar favorecendo a disseminação da planta e não a engorda dos animais. É possível que isto possa ser um sinal de alerta da própria natureza (MARÇAL, 2001).

\section{Conclusões}

1) a samambaia foi responsável pela toxidez aguda e óbito de 25 bovinos naquela propriedade rural;

2) as fortes geadas ocorridas entre os dias 13 e 24 de julho de 2000 , dizimaram as pastagens e favoreceram a brotação da samambaia como única massa verde disponível aos animais a campo;

3) prejuízos econômicos poderão ocorrer constantemente, enquanto não se desenvolver medidas eficientes e econômicas na erradicação ou controle da samambaia nas áreas de pastagens de bovinos, com respeito ao meio ambiente, que deve ser recuperado com urgência naquela localidade, onde a planta se disseminou rapidamente.

\section{Referências}

BASILE, J. R.; GASTE, L.; REIS, A.C.F. Intoxicação aguda de bovinos pela samambaia (Pteridium aquilinum) no estado do Paraná. Revista de Ciências Agrárias, Curitiba, v.3, p.167-170, 1981.

BUENO, P. Papilomatose faringeana em bovinos. $O$ Biológico, São Paulo, v.19, n.1, p.8-10,1953.

BRASIL. Ministério da Agricultura e do Abastecimento: Calendário Oficial de Exposições e Feiras Agropecuárias: Brasil. Brasília: MA/SBMV 2000.

CAMPOS NETO, O.; BARROS, H. M.; BICUDO, P. L. Estudo do carcinoma do trato digestivo superior e da hematúria enzoótica dos bovinos na região de Botucatu-SP. Arquivos da Escola de Veterinária da UFMG. v.27, n.2, p.125-139, 1975.

CLARKE, E. G. C.; CLARKE, M. D. Veterinary Toxicology. Baltimore Md.: Willians \& Wilkins, p.301-307, 1975.

DURÃO, J. F. C. et al. Aspectos anatomopatológicos e clínicos da hematúria enzoótica dos bovinos. Revista Portuguesa de Ciências Veterinárias v.5, n.1, p.11-20, 1995.

EVANS, W. C.; EVANS, E.T.R.; HUGHES, L.E. Studies on bracken fern poisoning in cattle. Part 1. British Veterinary Journal, v.110, p.295-306,1954a.

EVANS, W. C.; EVANS, E.T.R.; HUGHES, L.E. Studies on bracken fern poisoning in cattle. Part 2. British Veterinary Journal, v.110, p.365-380,1954b.

EVANS, W. C.; EVANS, E.T.R.; HUGHES, L.E. Studies on bracken fern poisoning in cattle. Part 3. British Veterinary Journal, v.110, p.426-444,1954c.

EVANS, I. A.; HOWELL, R. M. Bovine bracken poisoning. Nature, v.194, n.4828, p.584-585, 1962.

FERREIRA, J. C. V. O Paraná e seus municípios, p.569570, 1996.

GIBBONS, W. J. Bracken poisoning. American Veterinary Publician, p.518-520, 1956. 
HAGAN, W. A . Bracken poisoning of cattle. Cornell Veterinarian, v.15, p.326-332,1952.

HAYASHI, T. Aplication of jamshidi's needle to bone narrow biopsy and diagnosis of bracken poisoning in cattle. Journal of the Japan Veterinary Medical Association, v.34, p.206211, 1981.

HIRONO, I. et al. Comparative carcinogenic activity of in each part of bracken. Journal of Nacional Cancer Institute, v.50, n.5, p.1367-1371, 1973.

HOPKINS, N. C. G. Aetiology of enzootic haematuria. The Veterinary Record, London, v.118, p.715-717, 1986.

HUMPHREYS, D.J. et al. Veterinary toxicology. 3.ed. London: Baillere Tindall,1988. Cap.7: Poisonous plants: Pteridium aquilinum, p.258-262.

INSTITUTO AGRONÔMICO DO PARANÁ (IAPAR). Relatório pluviométrico. Londrina: IAPAR, 2001.

LACAZ, S.J. Cistite hemorrágica ou hematúria crônica dos bovídeos. O Biológico, São Paulo, v.20, n.4, p.64-65, 1954.

MARÇAL, W. S. Samambaia em pasto é veneno. Folha Rural, Londrina, n.718, p.13, 24/3/1990.

MARÇAL, W. S. A toxidez da samambaia nos bovinos. Disponível em: http: //<www.saudeanimal. com.br/bovinosamambaia.htm. Acesso em: 20 set. 2000

MARÇAL, W. S.; GASTE, L; BALARIN, M. R. S. Perspectiva terapêutica para a hematúria enzoótica dos bovinos. I Estudo clínico preliminar. XLVI CONFERÊNCIA ANUAL DA SOCIEDADE PAULISTA DE MEDICINA VETERINÁRIA, Anais... São Paulo, 1991, p.48.

MARÇAL, W. S. Estudo clínico da toxidez pela samambaia em bovinos no município de Reserva, estado do Paraná. Londrina, 2001. Anotações de campo.

MARÇAL, W. S; CAMPOS NETO, O. Condições nutricionais favoráveis à toxidez da samambaia nos bovinos. Revista Pecuária de Corte, n.61, p.94 a 96, nov. 1996.

MUSCA, M. S. et al. Histopathological and haematological studies in cows with enzootic haematuria. Revista Romana de Medicina Veterinária, v.7, n.3, p.241-245, 1997.

NIERO, L. et al. Surto de intoxicação aguda em bovinos pela ingestão de samambaia (Pteridium aquilinum, L. Kuhn) no norte do Paraná. In: SIMPÓSIO DE ESTAGIÁRIOS DO CCB/UEL, 9. 1991, Londrina. Anais... Londrina, [1991]. p. PATOL 90.

OINONEM, E. The correlation between the size of finish bracken Pteridium aquilinum (L) Kuhn clones and certain periods of site story. Acta Forestalia Fennica, v.83, n.2, p.1$51,1967$.
OliveirA, G. P.; MATSUMOto, T. ; PRimaVesi, A. C. Ocorrência de intoxicação causada por samambaia (Pteridium aquilinum) na região nordeste do Paraná. Comunicado Técnico Embrapa, São Carlos, n.20, p.1-9, out.1998.

PAGE, C. N. The taxonomy and phitogeography of bracken - A Review. Botanical Journal of the Linnean Society, v.73, p.01-34, 1976.

PAMUKCU, A. M.; PRICE, J. M.; BRYAN, G.T. Naturally ocurring and bracken - fern - induced bovine urinary bladder tumors. Veterinary Pathologic, v.13, p.110-122,1976.

PARKER, W. H.; McCREA, C. T. Bracken (Pteris aquilina) poisoning of sheep in the Nort York Moors. The Veterinary Record, v.77, p.861-866, 1965.

POLACK, E.W. Toxicidade da Pteridium aquilinum no Estado do Paraná. Dissertação (Mestrado) - UFPR, Curitiba, 1990. 102p.

RIET-CORREA, F.; MÉNDEZ, M.C.; SCHILD, A.L. Intoxicação por plantas e micotoxicoses em animais domésticos. Rio Grande do Sul: Varela, 1993. p.340.

REICHMANN, C. E. Hematúria enzoótica dos bovinos. São José do Rio Preto, 1975. Palestra proferida.

SINGH, A. K; JOSHI, H. C; RAY, S. N. Serum mucoprotein and silical acid in enzootic bovine haematuria. Zentralblattfur-Veterinarmedizin, v.27 A, n.8, p.678-681, 1980.

SIPPEL, W . L . Bracken fern poisoning. Journal of the American Veterinary Medical Association, v.21, p.09-13, 1952.

SOUZA, M. V.; GRAÇA, D. L. Intoxicação crônica por Pteridium aquilinum em Bovinos. Ciência Rural, Santa Maria, v.23, n.2, p.203-207, 1993.

TOKARNIA, C. H.; DOBEREINER, J.; CANELLA, C. F. C. Ocorrência de intoxicação aguda pela "samambaia" (Pteridium aquilinum) em bovinos no Brasil. Pesquisa Agropecuária Brasileira, v.2, p.329-336, 1967.

TOKARNIA, C. H.; DOBEREINER, J.; BARROS, S. S. Plantas tóxicas do Brasil. Região Sul. Folheto. UFRRJ, MA/RJ. EMBRAPA/RJ, 1979.

TOKARNIA, C. H.; DOBEREINER, J.; PEIXOTO, P.V. Plantas tóxicas do Brasil. Rio de Janeiro: Helianthus, 2000. p.310.

TUMA, M. M. P. Viver é descobrir. história, geografia: Paraná. São Paulo: FTD, 1992.

YAMANE, O; HAYASHI, T; SAKU, S. Studies on blood coagulation disorders in domestic animals thrombelastograms of normal cattle and cattle affected with bracken poisoning. Japanese Journal of Veterinary Science, v.37, p. 577-583, 1975. 